\title{
Do Optometrists Screen for Glaucoma?
}

\author{
S. A. VERNON ${ }^{1}$ and D. J. HENRY ${ }^{2}$ \\ Nottingham
}

\begin{abstract}
Summary
A survey of optometrists practising in Nottingham was undertaken to identify their methods of screening for glaucoma in the community. There was found to be great variation in all parameters examined including referral criteria. Although all of the respondents screened for glaucoma, $\mathbf{5 0} \%$ appeared not to be aware of subtle optic disc signs of the disease, $8 \%$ never measured intra-ocular pressures and $19 \%$ never performed visual field analysis. In a general practice population age 50 and over, $73 \%$ of patients had visited their optician within the last two years, $67 \%$ knew glaucoma was an eye disease, but only $15 \%$ remembered being screened for glaucoma.
\end{abstract}

Chronic simple glaucoma (CSG) is a major cause of blindness in the western world, ${ }^{1}$ is asymptomatic in most cases until extensive loss of peripheral visual field occurs ${ }^{2}$ and the prevalence increases with age from $0.5-1 \%$ of the population over $40,{ }^{3}$ rising to over $6 \%$ in the $75+$ age group. ${ }^{4}$

Optometrists initiate referral to an ophthalmologist in cases of suspect glaucoma in around $70 \%$ of cases ${ }^{5}$ but in one multicentre study, $33 \%$ of patients with CSG were found to present late in the course of the disease. ${ }^{6}$ The ophthalmologist therefore becomes involved when it may be difficult to prevent progress towards blindness.

If optometrists are to remain the main screening force for glaucoma in the community following the introduction of charges for sight tests, detection of the disease in its asymptomatic stage will depend on the frequency with which patients in the age group most at risk visit their optometrist and the sen- sitivity and specificity of the screening procedures used.

Once the decision to screen an individual for glaucoma has been made, optometrists use the following procedures either alone or in any combination-

(1) Optic disc examination

(2) Intraocular pressure (IOP) measurement

(3) Visual field analysis

To identify the frequency of use of each method in Nottingham, an anonymous questionnaire was sent to all optometric practices with a Nottingham telephone number who advertised in the classified directory.

In addition, as part of a project designed to test the sensitivity and specificity of screening for glaucoma in the community, patients of a single handed General Practitioner who were aged 50 and over were sent a letter with an appointment for the screening clinic. On attending, they were questioned about their

From: ${ }^{1}$ Academic Unit in Ophthalmology, University Hospital, Nottingham and ${ }^{2}$ Department of General Practice, University of Nottingham.

Correspondence to: Mr S. A. Vernon FRCS FCOphth, Senior Lecturer in Ophthalmology, University Hospital, Nottingham NG7 2UH. 
previous visits to an optometrist and their understanding of the word 'Glaucoma'. Patients who were registered blind, or were known to have glaucoma or dementia were excluded from the study.

\section{Results}

Of the 48 questionnaires sent, 26 were returned for analysis (54\%). All 26 of the optometrists who replied said they screened for glaucoma. The percentage of optometrists who would have routinely screened a patient of a certain age is shown in Fig. 1.

Optometrists were asked when they would screen at an earlier age. Of the 21 who commenced screening at 40 or over, 17 of these $(81 \%)$ took family history into account, nine $(43 \%)$ mentioned symptoms and two $(10 \%)$ would screen if the patient requested a test.

All optometrists used direct ophthalmoscopy as a screening method, and in two cases $(8 \%)$ this was the only method used. Optometrists were asked to list the features of a disc that would lead them to suspect glaucoma, with the most important feature first. Optometrist responses to this question are shown in Table I. Fifty per cent of the respondents failed to mention any sign at the optic disc other than pallor and cupping.

All but two of the 26 optometrists measured the intraocular pressure (IOP). Seventeen of the $24(71 \%)$ used a noncontact tonometer (NCT), two measured four readings per eye, nine of these measured three readings, four measured two and two only one. The seven others who measured IOP used a contact tonometer, either a Goldmann or Perkins applanation device.

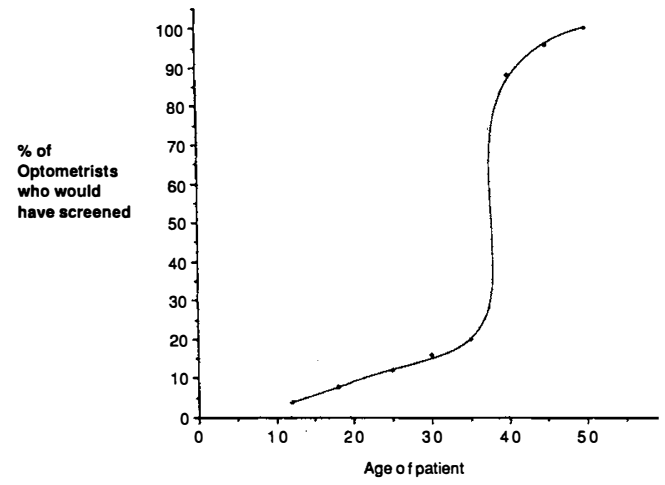

Fig. 1-Probability of routine screening by optometrist byage.
Three optometrists who measured IOP would not commit themselves as to when referral would be indicated. The percentage of optometrists who would have referred a patient with a particular IOP on the grounds of an elevated IOP alone is shown in Fig. 2. From this graph, the probability of a patient being referred at a particular pressure can be estimated.

The criteria used by optometrists when making the decision to perform a visual field are shown in Table II.

Of those who performed field analysis, 14 out of $21(67 \%)$ used one of the many semiautomated central field analysers, six used the Bjerrum screen and one used confrontation.

In the general practice study, 988 patients aged 50 and above were interviewed when they attended their screening appointment. This represents $88.5 \%$ of the eligible population of the practice. Forty-six per cent had attended an optometrist within the last year, with a further $27 \%$ between one and two years. Twenty-six per cent had seen their optician over two years ago and $1 \%$ had never seen one. Sixty-seven per cent knew glaucoma was an eye disease but only $15 \%$ of those who did remembered ever having had a test for it or having had any test similar to one of those used in the study (NCT and semiautomated visual field analysis).

\section{Discussion}

Optometrist referrals for 'query glaucoma' account for between $5 \%$ and $13 \%$ of a general ophthalmologist's new patient workload ${ }^{7,8}$. The diagnostic false positive rate of optometrists when referring for glaucoma or sus-

Table I. Optometrist's recognition of glaucomatous discs

\begin{tabular}{lcc}
\hline Abnormal sign & $\begin{array}{c}\text { No reporting } \\
(n=26)\end{array}$ & \% of total \\
\hline $\begin{array}{l}\text { Cupping or abnormal } \\
\quad \text { cup/disc ratio }\end{array}$ & 24 & 92 \\
$\begin{array}{l}\text { Disc pallor } \\
\text { Retinal vessel } \\
\text { displacement }\end{array}$ & 19 & 73 \\
$\begin{array}{l}\text { Disc asymmetry } \\
\text { Disc haemorrhage }\end{array}$ & 13 & 50 \\
Loss of the nerve fibre & 9 & 35 \\
$\quad$ layer & 5 & 19 \\
\hline
\end{tabular}




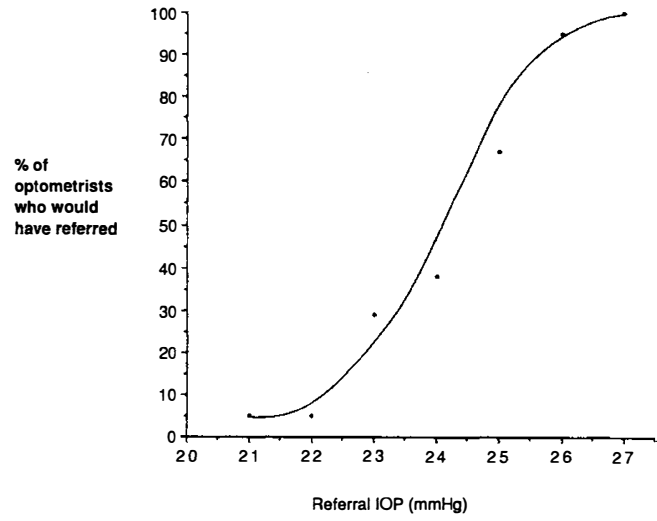

Fig. 2-Probability of referral by an optometrist on IOP grounds alone.

pect glaucoma varies from $56 \%{ }^{7}$ through $44 \%{ }^{5}$ down to $20 \%{ }^{8}$ and will depend on the threshold for referral and the ophthalmologist's definition of normal. To our knowledge, there is no available data on the false negative rate of the optometrist screening service and therefore the sensitivity and specificity of this system is unknown.

It has been suggested that ophthalmoscopy identifies most asymptomatic patients with glaucoma ${ }^{9}$ and some optometrists appear to be relying on this method of screening alone. It is interesting and perhaps worrying, therefore, that $50 \%$ of optometrists in our study did not mention any of the more subtle changes that occur in the disc in early glaucoma.

Sixty-four per cent of optometrist referrals found to be glaucoma positive are symptomatic ${ }^{10}$ indicating that only $36 \%$ are identified by routine screening. As $73 \%$ of a representative sample of the population over the age of 50 attend their optician at least every two years and glaucoma is thought to progress slowly in the majority of cases, it would appear that there is room for some improvement in the present system of glaucoma detection.

The optometrists' code of practice requires them to refer to a medical practitioner any abnormality found on ocular examination and this would clearly include a finding of glaucoma or suspect glaucoma.

To establish a diagnosis of glaucoma, it is necessary to interpret information on all three parameters of the disease; intraocular pres- sure, discs and fields. In our study, optometrists were found to vary considerably in their measurement and assessment of intraocular pressure. Thirty-five per cent of those who used a NCT measured only one or two readings per eye when the accepted number is three or preferably four ${ }^{11,12} ; 8 \%$ did not measure the IOP at all and $29 \%$ of those who did would not refer until the IOP was $>25$ $\mathrm{mmHg}$, presumably in a desire not to over refer if other parameters were 'normal'.

Evidence is accumulating that many patients with IOPs $>21 \mathrm{mmHg}$ and normal visual fields, at present defined as 'ocular hypertensives', have defects in visual function that may precede field loss ${ }^{13,14}$. Indeed it is considered that $40-50 \%$ of the nerve fibres in the optic nerve are destroyed prior to the onset of field loss that can be detected by routine perimetry. ${ }^{15}$

Very few $(8 \%)$ of the optometrists in our study routinely performed visual field analysis despite most having access to suitable equipment. Patients who have progressed to a stage of early field loss and who are asymptomatic may, therefore, be being missed if the disc appearance is misinterpreted and the IOP is not 'raised'.

It would appear from the results of our study based on data from optometrists who returned the questionnaire, and who perhaps represent those more interested in screening for glaucoma, that there is much variation in how an individual is screened, and in the referral criteria applied. Such variations may be partly responsible for the late presentation of many glaucoma sufferers.

In a recent assessment of referrals to a hospital clinic for 'query glaucoma', Harrison attempted to determine how optometrists were screening by analysing their referral let-

Table II. Optometrist's criteria for visual field analysis

\begin{tabular}{lcc}
\hline Criteria & No $(n=26)$ & $\%$ of total \\
\hline $\begin{array}{l}\text { Performed field routinely } \\
\text { Only when disc abnormal }\end{array}$ & 2 & 8 \\
$\quad$ and IOP raised & 5 & 19 \\
When disc abnormal or & & \\
IOP raised & 14 & 54 \\
Never performed field & 5 & 19 \\
& 26 & 100 \\
\hline
\end{tabular}


ters. ${ }^{8}$ Although this method presumes all data will appear in the referral note to the GP, it would appear that only $12 \%$ of patients in their study had all three standard parameters assessed before referral.

Screening for occult disease is becoming increasingly popular but to be effective, it has to be accepted by the population. ${ }^{16}$ It is encouraging that nearly $90 \%$ of a population aged 50 years and over accepted an invitation to be screened for glaucoma in a general practice setting, although only $67 \%$ of those screened had previously been aware of the condition. Even allowing for some lapses of memory, it is surprising that only $15 \%$ of this group remembered being screened at any time in the past by their optometrist.

If ophthalmologists consider glaucoma screening to be desirable, then guidelines concerning the methods to be used, the frequency of the screening process and the indications for referral should be devised. These may require modification in the light of future advances but should be designed to increase both the sensitivity and specificity of the present system without overloading the Hospital Eye Service. At present optometrists determine their own referral criteria but, probably in an effort not to over refer, many early cases may be being missed.

In order to define suitable referral criteria for a modern, cost-effective glaucoma screening service, population studies are required, preferably utilising the rapid, non-invasive techniques employed by some optometrists. We are at present performing a pilot study in the community to determine these criteria.

The authors acknowledge financial assistance from the International Glaucoma Association in the General Practice Study.

\footnotetext{
References

${ }^{1}$ Ghafour IM, Allan D, Foulds WS: Common causes
}

of blindness and visual handicap in the West of Scotland. Br J Ophthalmol 1983, 67: 209-13.

${ }^{2}$ Galloway NR: Clinical types of Glaucoma-in Common Eye Diseases and their Management. Heidelberg Springer-Verlag 1985, 122-3.

${ }^{3}$ Hollows FC and Graham PA: Intraocular pressure, glaucoma and glaucoma suspects in a defined population. Br J Ophthalmol 1966, 50: 570-6.

${ }^{4}$ Gibson JM, Rosenthal AR, Lavery J: A study on the prevalence of eye disease in the elderly in an English Community. Trans Ophthalmol Soc UK 1985, 104: 196-203.

${ }^{5}$ Brittain GPH and Austin DJ: A prospective survey to determine sources and diagnostic accuracy of glaucoma referrals. Health Trends 1988, 20: 43-4.

${ }^{6}$ Elkington AR, Lewry J, MacKean J, Sargent P: A collaborative hospital glaucoma survey. Res Clin Forums 1982, 4: 31-40.

${ }^{7}$ Clearkin L and Harcourt B: Referral pattern of true and suspected glaucoma to an adult outpatient clinic. Trans Ophthalmol Soc UK 1983, 103: 284-7.

${ }^{8}$ Harrison RJ, Wild JM, Hobley AJ: Referral patterns to an ophthalmic outpatient clinic by general practitioners and ophthalmic opticians the role of these professions in screening for ocular disease. Br Med J 1988, 297: 1162-7.

${ }^{9}$ Hitchings RA: Screening for glaucoma. $\mathrm{Br}$ Med $\mathrm{J}$ 1986, 292: 505-6.

${ }^{10}$ Steinmann WC: The "Who" and "How" of detecting glaucoma. Br Med J 1982, 285: 1091-3.

${ }^{11}$ Fisher JH, Watson PG, Spaeth G: A new hand held air impulse tonometer. Eye 1988, 2: 238-42.

${ }^{12}$ Vernon SA: Non-contact tonometry in the Postoperative eye. Br J Ophthalmol 1989 73: 247-9.

${ }^{13}$ Ross JE, Bron AJ, Reeves BC, Emmerson PG: Detection of optic nerve damage in ocular hypertension. Br J Ophthalmol 1985, 69: 897-903.

${ }^{14}$ Gunduz K, Arden GB, Perry S, et al. Colour vision defects in ocular hypertension and glaucomaQuantification with a computer driven colour television system. Arch Ophthalmol 1988, 106: 929-35.

${ }^{15}$ Quigley HA and Green WR: The histology of human glaucoma cupping and nerve damage 111 Quantatitive correlation of nerve fibre loss and visual field defect in glaucoma, ischaemic neuropathy, papilloedema and toxic neuropathy. Arch Ophthalmol 1982, 100: 135-46.

${ }^{16}$ Wilson JMG and Jungner G: Principles and practice of screening for disease. Public Health Paper No.34 Geneva WHO 1968. 